\title{
Convergence of developmental mutants into a single tomato model system: 'Micro-Tom' as an effective toolkit for plant development research
}

\author{
Rogério F Carvalho ${ }^{1 \dagger}$, Marcelo L Campos ${ }^{1 \dagger}$, Lilian E Pino ${ }^{1,2}$, Simone L Crestana ${ }^{1}$, Agustin Zsögön ${ }^{1}$, Joni E Lima ${ }^{1,2}$,
} Vagner A Benedito ${ }^{3}$ and Lázaro EP Peres ${ }^{1 *}$

\begin{abstract}
Background: The tomato (Solanum lycopersicum L.) plant is both an economically important food crop and an ideal dicot model to investigate various physiological phenomena not possible in Arabidopsis thaliana. Due to the great diversity of tomato cultivars used by the research community, it is often difficult to reliably compare phenotypes. The lack of tomato developmental mutants in a single genetic background prevents the stacking of mutations to facilitate analysis of double and multiple mutants, often required for elucidating developmental pathways.

Results: We took advantage of the small size and rapid life cycle of the tomato cultivar Micro-Tom (MT) to create near-isogenic lines (NILs) by introgressing a suite of hormonal and photomorphogenetic mutations (altered sensitivity or endogenous levels of auxin, ethylene, abscisic acid, gibberellin, brassinosteroid, and light response) into this genetic background. To demonstrate the usefulness of this collection, we compared developmental traits between the produced NILs. All expected mutant phenotypes were expressed in the NILs. We also created NILs harboring the wild type alleles for dwarf, self-pruning and uniform fruit, which are mutations characteristic of MT. This amplified both the applications of the mutant collection presented here and of MT as a genetic model system.
\end{abstract}

Conclusions: The community resource presented here is a useful toolkit for plant research, particularly for future studies in plant development, which will require the simultaneous observation of the effect of various hormones, signaling pathways and crosstalk.

Keywords: hormonal mutants, Solanum lycopersicum, model organism, photomorphogenesis, plant development

\section{Background}

In addition to its worldwide cultivation and economic importance, tomato (Solanum lycopersicum L.) has several characteristics that make it a convenient model plant species, such as a relatively compact genome (950 $\mathrm{Mb})$ combined with a marker-saturated genetic linkage map [1], rich germplasm collections (Tomato Genetics Resource Center) [2] and highly efficient transformation

\footnotetext{
* Correspondence: lazaropp@esalq.usp.br

+ Contributed equally

${ }^{1}$ Laboratory of Hormonal Control of Plant Development, Department of Biological Sciences (LCB), Escola Superior de Agricultura "Luiz de Queiroz" (ESALQ), Universidade de São Paulo (USP) - Av. Pádua Dias, 11, CP 09, CEP 13418-900 Piracicaba - SP, Brazil

Full list of author information is available at the end of the article
}

protocols [3]. The pre-released annotated genome sequence [1] appears set to establish tomato as a prominent model system for research into plant genetics and physiology. The tomato is poised to become an alternative model plant to Arabidopsis thaliana due to its diverse developmental traits not found in Arabidopsis. These traits include: the photoperiod-independent sympodial flowering and the formation of fleshy climacteric fruits, compound leaves, mycorrhizal roots and glandular trichomes.

The convenient small size and amenability to largescale cultivation of Arabidopsis are also found in tomato cv. Micro-Tom (MT) [4]. MT was initially created for ornamental purposes [5], but its rapid life cycle and

\section{Ciomed Central}


high-throughput capabilities indicate that MT is a candidate cultivar as tomato's model system [6]. Regardless of the presence of mutations that cause the MT's dwarf size, it has been proven to be suitable as a standard genotype in tomato research [see 3, 7], including the study of novel hormonal interactions $[8,9]$.

Mutants are the most classical and probably the most reliable genetic tool for accessing biological information in a living organism. The plethora of mutants available in tomato is another advantageous characteristic of this model plant [10]. However, as for every model organism, comparative studies using tomato mutants tend to be limited by the difference in genetic backgrounds, given that the same gene function can have diverse effects depending on epistatic interactions with other genes $[11,12]$. In tomato, most of the known mutations are distributed in various genetic backgrounds including heirlooms, hybrids, and wild species [2].

By using a series of backcrosses, we introduce a rich collection of tomato hormonal and phytochrome mutants introgressed into a unique background, the MT cultivar. Merging the benefits of MT and the vast range of already well-characterized mutations, this collection encompasses a powerful and ready-to-use toolkit for studying plant genetics and physiology, allowing comparisons between different mutants without the issue of background noise. To emphasize the potential of this toolkit, we also present novel observations made with the mutants, and review some published data in light of the present collection.

\section{Results}

The developmental mutant collection in the tomato cv. Micro-Tom

Reliable comparative studies of specific genes mutated in pathways leading to hormone deficiency or insensitivity, as well as response to light, can only be performed in a uniform genetic background [11]. Because of its benefits as a plant model with small size and rapid life cycle $[4,6]$, we chose the MT cultivar as the recurrent parental to introgress available hormonal (Table 1) and photomorphogenetic (Table 2) mutations. The introgression consisted of a series of successive back-crosses up to $\mathrm{BC}_{6}$ generation, when at least $99 \%$ of the plants' genome corresponds to MT (see Additional file 1: Figure S1 for an introgression scheme).

Plants were selected after each backcross based on known phenotypic characteristics of the mutants (described in the references in Table 1 and Table 2) and also the miniature and determinate growth habit of MT [13]. The description of the mutant phenotypes in their original genetic background can be found in the Tomato Genetics Resource Center (TGRC) website [2]. Some of the most conspicuous traits are shown in Figures 1 and 2

Table 1 Hormonal mutations introgressed into cv. Micro-Tom

\begin{tabular}{|c|c|c|c|c|}
\hline Mutant & $\begin{array}{l}\text { Hormonal } \\
\text { class }^{\mathrm{a}}\end{array}$ & Effect/Gene function & Origin & Reference \\
\hline diageotropica (dgt) & Auxin & $\begin{array}{l}\text { Low sensitivity. Defect in a cyclophilin biosynthesis gene (a } \\
\text { putative signal transduction component) }\end{array}$ & $\begin{array}{l}\text { LA1529 } \\
\text { CV. unknown }\end{array}$ & {$[14]$} \\
\hline Never ripe $(\mathrm{Nr})$ & Ethylene & Low sensitivity. Defective for an ethylene receptor & $\begin{array}{l}\text { LA0162 } \\
\text { cV. Pearson }\end{array}$ & {$[17]$} \\
\hline epinastic (epi) & Ethylene & Ethylene overproduction. Unknown gene function & $\begin{array}{l}\text { LA2089 } \\
\text { CV. VFN8 }\end{array}$ & {$[16]$} \\
\hline sitiens (sit) & $A B A$ & ABA deficiency. Defective for ABA-aldehyde oxidase & $\begin{array}{c}\mathrm{LA} 0574 \\
\text { CV. Rheinlands Ruhm }\end{array}$ & {$[26]$} \\
\hline flacca (flc) & $A B A$ & $\begin{array}{c}\text { ABA deficiency. Defective for maturation of ABA-aldehyde } \\
\text { oxidase Mo cofactor }\end{array}$ & $\begin{array}{c}\mathrm{LA} 0673 \\
\text { CV. Rheinlands Ruhm }\end{array}$ & {$[26]$} \\
\hline notabilis (not) & $\mathrm{ABA}$ & $\begin{array}{l}\text { ABA deficiency. Defective for NCED (carotenoid cleavage } \\
\text { enzyme). }\end{array}$ & $\begin{array}{l}\text { LA0617 } \\
\text { CV. Lukulus }\end{array}$ & {$[27]$} \\
\hline gibberellin deficient 1 (gib1) & GA & $\begin{array}{l}\text { GA deficiency. Defective for ent-copalyl diphosphate synthase } \\
\text { (CPS) }\end{array}$ & $\begin{array}{l}\text { LA2893 } \\
\text { cV. Moneymaker }\end{array}$ & {$[21]$} \\
\hline gibberellin deficient 2 (gib2) & GA & $\begin{array}{l}\text { GA deficiency. Defective for conversion of ent-7 } \alpha \text { - } \\
\text { hydroxykaurenoic acid to } \mathrm{GA}_{12} \text {-aldehyde }\end{array}$ & $\begin{array}{l}\text { LA2894 } \\
\text { CV. Moneymaker }\end{array}$ & {$[21]$} \\
\hline gibberellin deficien t3 (gib3) & GA & GA deficiency. Defective for ent-kaurene synthase (KS) & $\begin{array}{l}\text { LA2895 } \\
\text { cv. Moneymaker }\end{array}$ & {$[21]$} \\
\hline procera (pro) & GA & $\begin{array}{c}\text { Constitutive response. Contains a point mutation in a gene } \\
\text { that converts the VHVID putative DNA-binding domain of the } \\
\text { tomato DELLA gene into VHEID }\end{array}$ & $\begin{array}{l}\text { LA0565 } \\
\text { cV. Condine Red }\end{array}$ & {$[19]$} \\
\hline curl 3 (cu3) & $\mathrm{BR}$ & $\begin{array}{l}\text { Decreased sensitivity. Defective for BR receptor (LeBR/1) found } \\
\text { in S. pimpinellifolium }\end{array}$ & $\begin{array}{l}\text { LA2398 } \\
\text { wild species }\end{array}$ & {$[24]$} \\
\hline dumpy (dpy) & $\mathrm{BR}$ & $\begin{array}{l}\text { BR deficiency. Probably defective in the conversion of 6- } \\
\text { deoxocatasterone to 6-deoxoteasterone }\end{array}$ & $\begin{array}{l}\text { LA0811 } \\
\text { CV. unknown }\end{array}$ & {$[23]$} \\
\hline
\end{tabular}

\footnotetext{
${ }^{\mathrm{a}} \mathrm{ABA}=$ abscisic acid; $\mathrm{GA}=$ gibberellin; $\mathrm{BR}=$ brassinosteroid
} 
Table 2 Photomorphogenic mutations introgressed into cv. Micro-Tom

\begin{tabular}{|c|c|c|c|c|}
\hline Mutants & Mutation & Gene function & Origin & Reference \\
\hline aurea (au) & $\begin{array}{l}\text { Deficiency in phytochrome } \\
\text { chromophore biosynthesis }\end{array}$ & $\begin{array}{l}\text { Defective for the phytochromobilin synthase } \\
\text { gene }\end{array}$ & $\begin{array}{c}\text { LA3280 } \\
\text { cv. Ailsa Craig }\end{array}$ & {$[31]$} \\
\hline yellow green 2 (yg2) & $\begin{array}{l}\text { Deficiency in phytochrome } \\
\text { chromophore biosynthesis }\end{array}$ & $\begin{array}{l}\text { Probably defective for the heme oxygenase } \\
\text { gene }\end{array}$ & $\begin{array}{l}\text { LA2514 } \\
\text { Cv. unknown }\end{array}$ & {$[32]$} \\
\hline high pigment 1 (hp1) & Increased response to light & $\begin{array}{c}\text { Defective for a gene homologous to DDB1A of } \\
\text { Arabidopsis, which codes a protein interacting } \\
\text { with DET1 (HP2), a repressor of } \\
\text { photomorphogenesis }\end{array}$ & $\begin{array}{l}\text { LA3004 } \\
\text { cV. Rutgers }\end{array}$ & {$[35]$} \\
\hline high pigment 2 (hp2) & Increased response to light & $\begin{array}{c}\text { Defective for a gene homologous to DET1 of } \\
\text { Arabidopsis, a negative repressor of } \\
\text { photomorphogenesis }\end{array}$ & $\begin{array}{c}\text { LA2451 } \\
\text { CV. Manapal }\end{array}$ & [36] \\
\hline atroviolacea (atv) & Increased response to light & $\begin{array}{c}\text { Natural variation from S. cheesmaniae, probably } \\
\text { a non-functional allele of a negative regulator } \\
\text { of photomorphogenesis }\end{array}$ & $\begin{array}{l}\text { LA0797 } \\
\text { Hybrid }\end{array}$ & {$[38]$} \\
\hline Intense pigment (Ip) & Increased response to light & $\begin{array}{c}\text { Natural variation from S. chmielewskii, probably } \\
\text { a positive regulator of light response, whose } \\
\text { tomato allele is non-functional }\end{array}$ & $\begin{array}{l}\text { LA1563 } \\
\text { Hybrid }\end{array}$ & {$[38]$} \\
\hline
\end{tabular}

for hormonal and photomorphogenetic mutants, respectively, as proof of concept that the introgressions were successful.

MT leaves usually have five leaflets, which are rarely hyponastic or epinastic, with slightly notched leaf margins (Figure 1A). On the other hand, leaves of the reduced auxin sensitivity mutant diageotropica (dgt) [14] introgressed into the MT background present severe hyponasty (Figure 1B). The dgt mutation in MT also led to the characteristic altered gravitropic response and reduced number of lateral roots (Figure 1G). These phenotypes agree with the role of auxin in plant development [14] and are also observable in the original $d g t$ parental line [15].

Leaf development is altered in the ethylene-overproducing mutant epinastic (epi) [16], which is thus named because of its severely epinastic (curled downward) leaves (Figure 1C). The curled leaves of epi in the miniature MT background resulted in a plant with barely visible stems (Figure 1H). The epi mutant also showed the exaggerated stem thickening and root branching (data not shown) observable in the parental plant as described by Fujino et al. [16].

Another ethylene mutation introgressed into MT was the reduced ethylene sensitivity Never ripe $(\mathrm{Nr})$ [17]. In the MT background $\mathrm{Nr}$ shows all traits typical of an ethylene insensitive mutant [18]. The ethylene triple response phenotype (thickening and shortening of hypocotyl with pronounced apical hook) is absent in MT-Nr seeds germinated in the presence of ethylene (Figure 1I), as reported for the mutant in the original background by [18]. Also absent in MT-Nr plants are senescence and abscission of leaves and flowers, with petals and anthers remaining attached even upon fruit development (not shown). The unripe fruit phenotype is the most representative trait of this mutant; $\mathrm{Nr}$ fruits linger with an orange/yellowish color (Figure 1J). In spite of this, seeds of MT-Nr are as viable as MT seeds (see below).

The monogenic recessive DELLA mutant procera (pro) [19], originally isolated in the cultivar Condine Red, leads to a constitutive gibberellin (GA) response phenotype which includes increased height, more elongated internodes, thinner leaves and reduced leaf lobing [20]. All of these phenotypes are evident in MT-pro (Figures $1 \mathrm{D}, 1 \mathrm{~K})$. Interestingly, we also observed that MT-pro plants have a higher tendency to form parthenocarpic and navel fruits, compared to MT (Figure 1L).

Three other GA mutants were introgressed: gibberellin-deficient 1, 2 and 3 (gib-1, gib-2 and gib-3). These mutants are disrupted at different points of the GA biosynthetic pathway [21] (Table 1 ). They require GA to germinate, develop flowers, set fruits and produce seeds in their original background [22], and all these traits have been maintained in the MT introgressed lines. Figure $1 \mathrm{M}$ shows the severe dwarfism of MT-gib2 (gib1 and gib3 present a similar phenotype - not shown), consistent with the expected phenotype for a GA mutant. The leaflet margins of these three GA defective mutants, as opposed to the excess-GA mutant pro and to MT, show a very serrated lobe pattern (Figure 1E for gib3).

Brassinosteroid (BR) mutants are generally severely dwarfed with extremely reduced and curled leaves, as in the tomato BR defective dumpy (dpy) [23] and the tomato BR insensitive curl3 (cu3) [24] mutants. The MT BR mutants $d p y$ and cu3 (Figure $1 \mathrm{~N}$ ) also showed reduced and curled leaves (Figure $1 \mathrm{~F}$ ), as expected. The introgression of these mutations in MT created what, to the best of our knowledge, are the smallest viable tomato lines described to date, with adult plants less than $3 \mathrm{~cm}$ tall. As mentioned above, gib mutants are also very small (Figure $1 \mathrm{M}$ ), but they do not produce seeds without exogenous GA application. Application of 


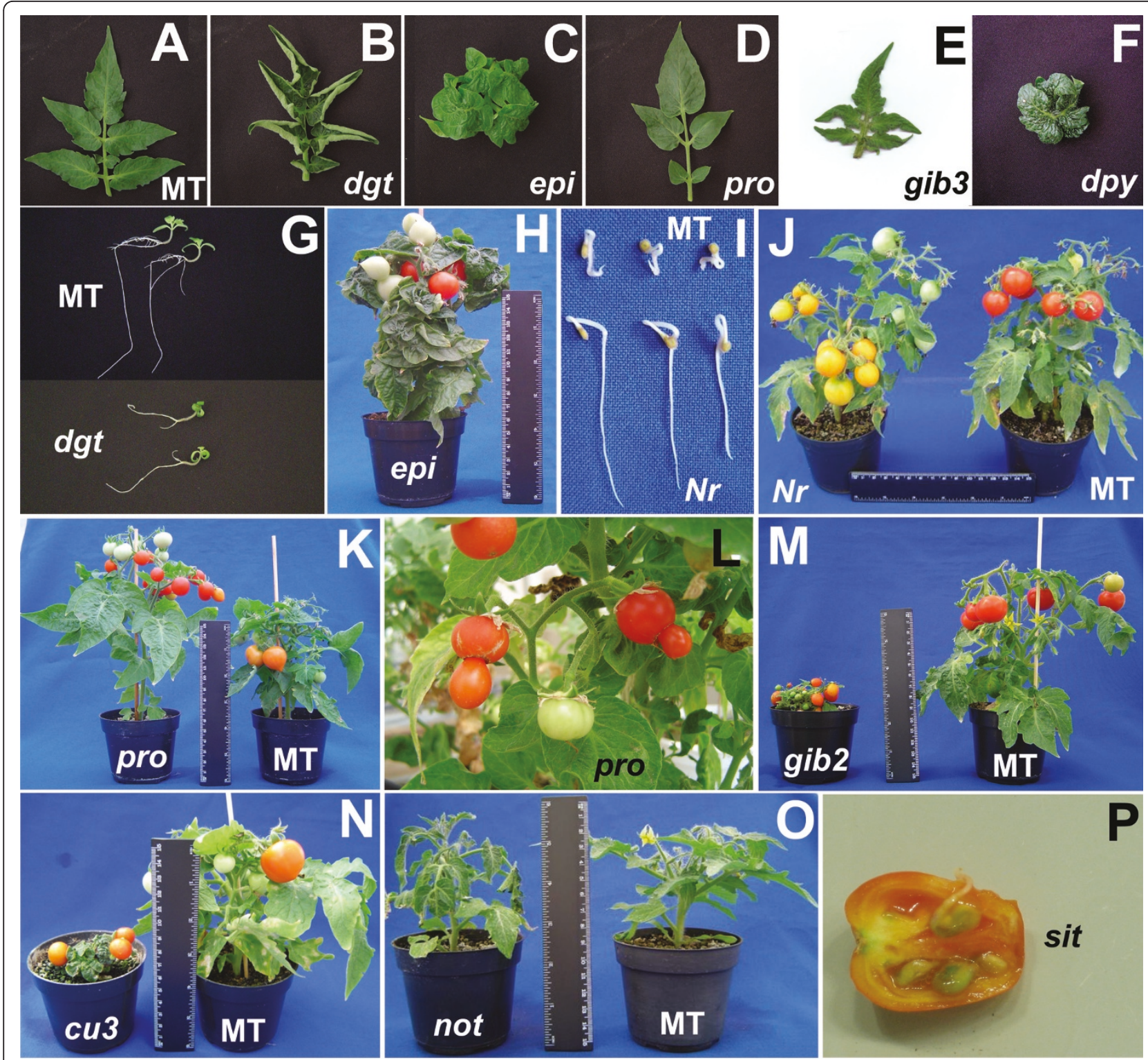

Figure 1 Phenotype of hormone mutants introgressed into cv. Micro-Tom (MT). Leaf phenotype of MT (A), dgt (B), epi (C), pro (D), gib3 (E) and $d p y(F)$. (G) Reduced gravitropic response and lateral root formation in 10-day old seedlings of the auxin mutant dgt when compared to MT. (H) Severe epinasty of the ethylene overproducer mutant epi in the MT background resulting in a phenotype where stems are hardly observable. (I) When growing in 200 ppm ethrel (an ethylene-releaser), MT seedlings show short roots and hypocotyls with exaggerated hook, a phenotype not observed in the ethylene low sensitive $\mathrm{Nr}$. (J) Nr also shows incomplete ripening, producing yellow fruits. (K) Phenotype of pro with increased stem elongation and navel fruits (L). (M and N) Phenotypes of gib2 (M) and CU3 (N), with severe plant size reduction and leaf expansion inhibition compared to MT. (O) ABA deficiency in notabilis leads to wilting during the hottest hours of the day. (P) Precocious germination (vivipary) in sit seeds within the fruit. A description of hormone alterations involved in each mutant can be found on Table 1. Ruler in $(H),(J),(K),(M),(N)$ and $(O)=15 \mathrm{~cm}$.

a bioactive BR, such as brassinolide, attenuates the phenotype of $d p y$, but not of cu3 [23].

Abscisic acid (ABA) is sometimes referred to as the "stress hormone" because of its involvement in many biotic and abiotic stress responses [25]. Three mutants impaired in ABA biosynthesis were introgressed in this work: sitiens and flacca (sit and flc respectively) [26], originally from the Rheinlands Ruhm cultivar, and notabilis (not) [27] introgressed into MT from cv. Lukullus. Consistent with the role of ABA in drought stress, and as observed in the parental lines, MT ABA-deficient mutants present severe wilting when exposed to a mild drought stress, as exemplified for not in Figure 1O. ABA also plays an important role in seed development and 


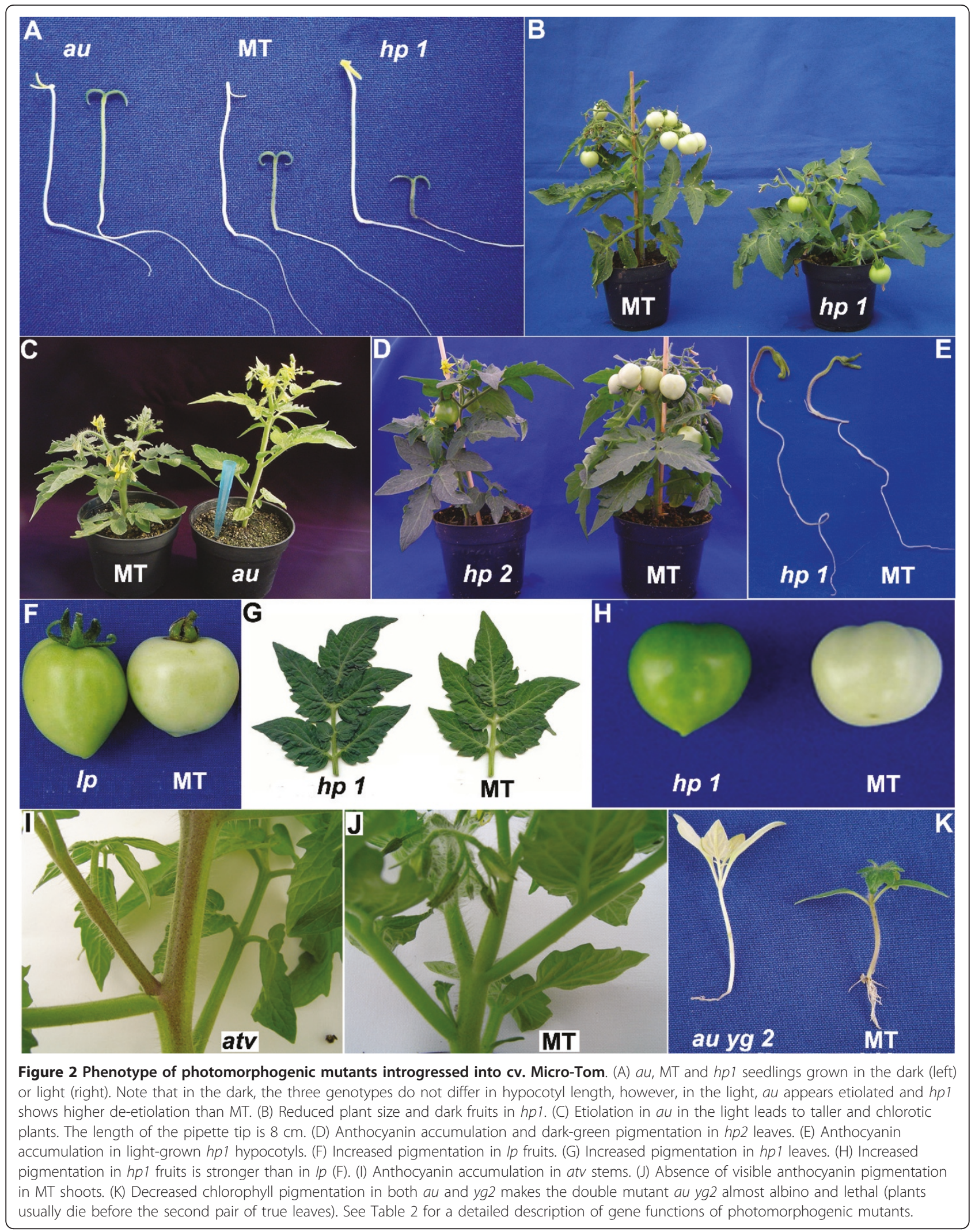


primary seed dormancy [28] and the ABA-deficient mutant seeds frequently showed vivipary (Figure 1P), which is more easily observable in sit than in not or flc.

Light is one of the most important environmental factors conveying information on the plants' environment, and irradiance can quickly alter plant development at various instances [29]. Phytochromes are photoreversible light perception proteins involved in seed germination, seedling establishment, de-etiolation, shade avoidance, flowering, and many other processes [30]. Two phytochrome-deficient mutants were introgressed into MT: aurea (au), a tomato mutant defective in one of the last steps of the phytochrome chromophore biosynthesis pathway [31] and yellow green 2 (yg2), which is probably defective for the heme oxygenase gene [32]. Both of these mutations can be readily identified by characteristic elongated hypocotyls and paler green leaves when grown under white light (as shown for $a u$ in Figures 2A and $2 \mathrm{C}$, respectively). The difference in height between these mutants [33] is more clearly revealed in the MT miniature background. As shown in Figure 2C for MT$a u$, these plants are taller than their MT parent. MT-au and MT-yg2 plants are also less branched than MT. Since the chromophore is common for all phytochrome types, it is presumed that $a u$ and $y g 2$ mutants present alterations in responses controlled by both type I ( $p h y A)$ and type II (phyB1, phyB2, phyE, phyF) phytochromes in tomato. The au yg2 double mutant has an additive chlorophyll deficiency (Figure 2K), confirming that both mutations are weak alleles controlling different steps in the chromophore biosynthetic pathway, as suggested by van Tuinen et al. [34].

The non-allelic tomato high pigment mutations high pigment 1 ( $h p 1)$ [35] and high pigment $2(h p 2)$ [36] were introgressed into the MT cultivar from cultivars Rutgers and Manapal, respectively. These monogenic recessive mutations have an exaggerated de-etiolation photoresponse. Both $h p 1$ (Figure 2A) and $h p 2$ seedlings present inhibition of hypocotyl elongation and intense anthocyanin accumulation (Figure 2E) when grown under white light [37]. Also conspicuous in both $h p 1$ and $h p 2$ are high chlorophyll pigmentation in leaves (Figure $2 \mathrm{G}$ for $h p 1$ and 2D for $h p 2$ ) and fruits (Figure 2H for $h p 1$, and also Figure $2 \mathrm{C}$ ). These phenotypes are in agreement with the known function of the HP1 and HP2 genes in the light signal transduction pathway (Table 2).

Natural genetic variation for light response, the atroviolacea (atv) and Intense pigment (Ip) [38] alleles were also brought into the MT genetic background. These mutants are phenotypically similar to $h p$ mutants, but map to different loci $[39,40]$. Derived from Solanum cheesmaniae, the atv mutant is characterized by an excess of anthocyanin in stems, leaves and fruits. Figure 2I shows the typical accumulation of this pigment in
MT-atv stems (Figure 2J). Ip is a mutation originally found in the wild tomato relative Solanum chmielewskii, which confers darker pigmentation in unripe and ripe fruits. This characteristic phenotype is present in the MT-Ip (Figure 2F).

\section{Comparative studies made easy using the MT developmental mutant collection}

A set of mutations harbored in a single genetic background allows comparative studies without having to deal with possible background-specific modifiers. To illustrate this point, we carried out some simple comparative experiments between our MT hormonal and photomorphogenetic mutants, recording several parameters during plant development, from seed germination to fruit set. The aim of these analyses was not to prove the involvement of a specific gene in a given biological process, but rather to demonstrate a general participation of a given hormone/ light response in plant development and as proof of concept for the usefulness of the collection in comparative studies. These results also provide further evidence confirming that the mutations were correctly introgressed.

\section{Seed germination}

Although virtually every hormone has been suggested to have a role in seed germination [41], the classic and antagonistic hormones associated with this process are GA and ABA, inducing and repressing seed germination, respectively [42]. The pro GA-constitutive mutant shows a significant reduction in time required for $50 \%$ germination, both in light and dark, compared to MT (Figure 3A, 3B). A similar effect was observed in the ABA-deficient not mutant (Figure 3A, 3B).

Besides ABA and GA, another hormone with a fundamental role in seed germination is ethylene [41]. Early germination was observed for the partially ethylene insensitive $\mathrm{Nr}$ mutation in the MT background, a result reported previously for tomato [41], but opposite to that observed in Arabidopsis ethylene insensitive mutants $[43,44]$. The ethylene overproducer epi, however, showed no difference with respect to MT (Figures 3A, $3 \mathrm{~B})$. The role of auxin in embryogenesis is well described, but little is known about its activity during seed germination [41]. The $d g t$ mutant (reduced sensitivity to auxin) showed an accelerated germination in the light but not in the dark (Figures 3A, 3B), suggesting an interaction with either phytochrome or other light receptors. The BR-deficient $d p y$ had a slow germination rate, significantly more so in the light than in the dark. This is not unexpected, as BR has been reported to promote germination [45]. Finally, the MT background did not affect the previously described response on seed germination time in photomorphogenic mutants, i.e. au has a slower germination [46], and $h p 1$ had no effect on germination time [47]. 

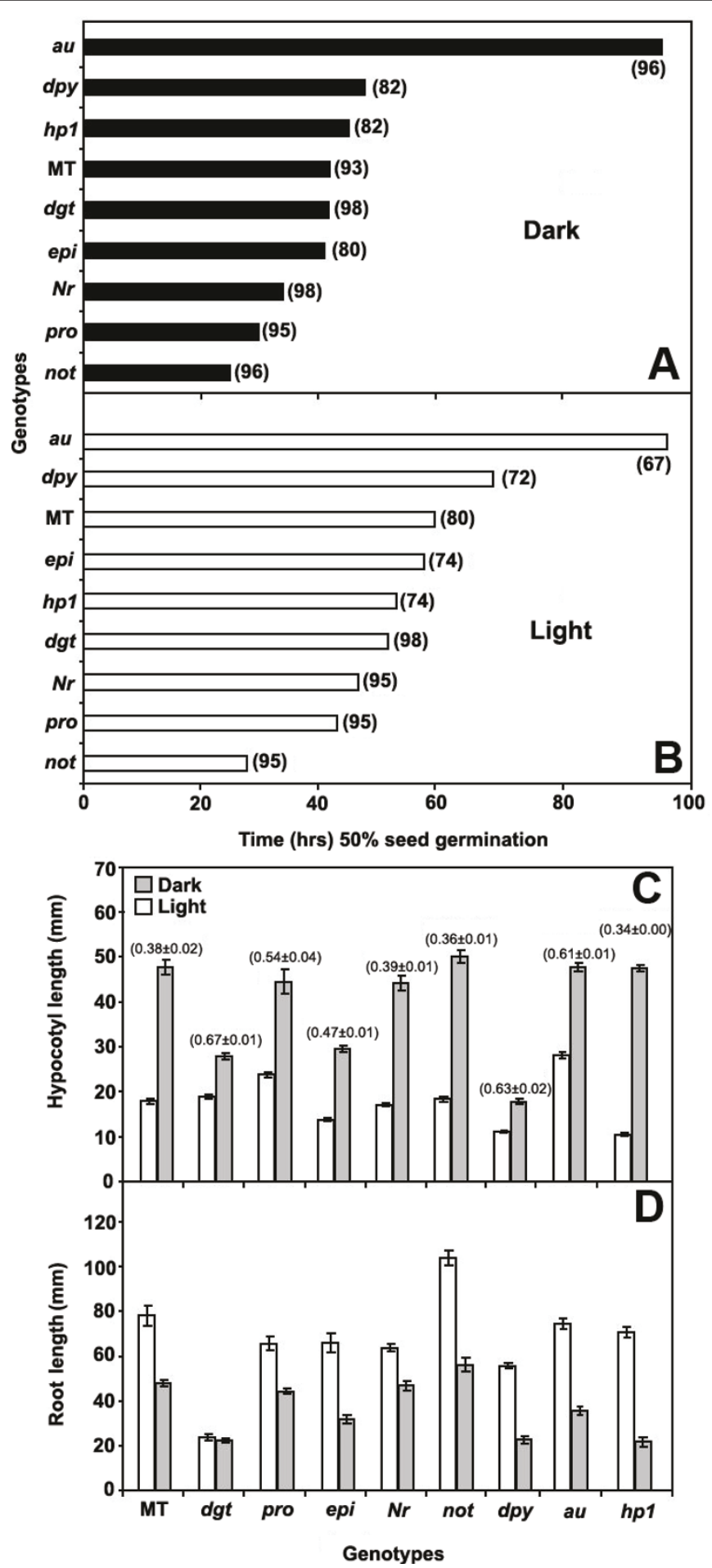

Figure 3 Seed germination and seedling growth in hormone and photomorphogenic mutants. (A-B) Time (days) to reach $50 \%$ germination of seeds in dark (A) or light (B). Final germination percentage is between brackets. (C-D) Hypocotyl and root length of light-grown (open bars) and dark-grown (closed bars) seedlings during 10 days. In (C), numbers between brackets represent the ratio between hypocotyl length in the light and dark. Vertical lines represent standard error ( $n=3 \times 50$ for germination and $n=20$ for hypocotyl and root length). 


\section{Hypocotyl elongation}

Light inhibits hypocotyl elongation through a signal transduction pathway starting with photoreceptors but whose downstream components are still to be unveiled [48]. Hormones are also strong candidates to participate in this pathway [49]. The ratio between the lengths of dark- and light-grown hypocotyls can be used as a parameter to screen for mutations affecting etiolation in the dark or de-etiolation in the light. Here, hypocotyl length of either light (16 h photoperiod) or dark-grown mutants was measured 10 days after germination. The phytochrome-deficient au mutant presented a reduced light inhibited growth (Figures 2A and 3C), but its etiolation in dark was equivalent to that of MT (Figure 3C). On the other hand, a mutant with exaggerated phytochrome response, $h p 1$, showed higher inhibition of hypocotyl elongation in the light (Figure $3 \mathrm{C}$ and see also Figure 2A). These results are in agreement with previous reports for these mutants $[34,47]$, and demonstrate that the MT background is not epistatically affecting the phenotype conferred by such mutations.

The hormonal mutants $d g t, d p y$, pro, and epi showed high ratios between hypocotyl lengths under light vs. dark, when compared to MT. The high value for pro can be attributed to the mutant having significant growth in the light (Figure 3C). On the other hand, the reduced difference between light and dark for $d g t$, epi, and $d p y$ is probably due to a higher inhibition of elongation in the dark (Figure $3 \mathrm{C}$ ). The requirement of auxin $(d g t)$ for elongation in the dark and the positive effect of GA (pro) under light, but not in the dark, have already been suggested for tomato and other model species [50,51]. Furthermore, the response of epi is consistent with ethylene's known inhibitory effect on hypocotyl elongation [52,53]. Although the BR-deficient mutant dpy presented a much reduced hypocotyl length in both conditions, the inhibition was higher in the dark (Figure 3C). This BR deficiency effect had been interpreted as a de-etiolated phenotype in the dark for Arabidopsis equivalent mutants [54].

\section{Primary root elongation}

Both reduced and enhanced root elongation were observed in $d g t$ and not mutants, respectively (Figure $3 \mathrm{D})$. These results are consistent with the suggestion that root growth can be regulated by a balance between auxin and ABA hormone classes [55]. Interestingly, the comparison of root elongation in the light or in the dark showed that root behavior is consistently opposite to the hypocotyl, i.e., primary root elongation is stimulated by light (Figure 3D). This effect could be due to a direct photomorphogenic effect, a source/sink effect, or a combination of both [56]. Whatever the correct explanation, the observed behavior favors light avoidance in tomato roots, the opposite and complementary response to dark avoidance in stems.

\section{Stem height and dry weight}

Hormone mutants presented significant differences in stem height and dry mass accumulation after 56 days of growth in greenhouse conditions (Figures 4A, 4B). Consistent with the roles of GA and auxin in cell division
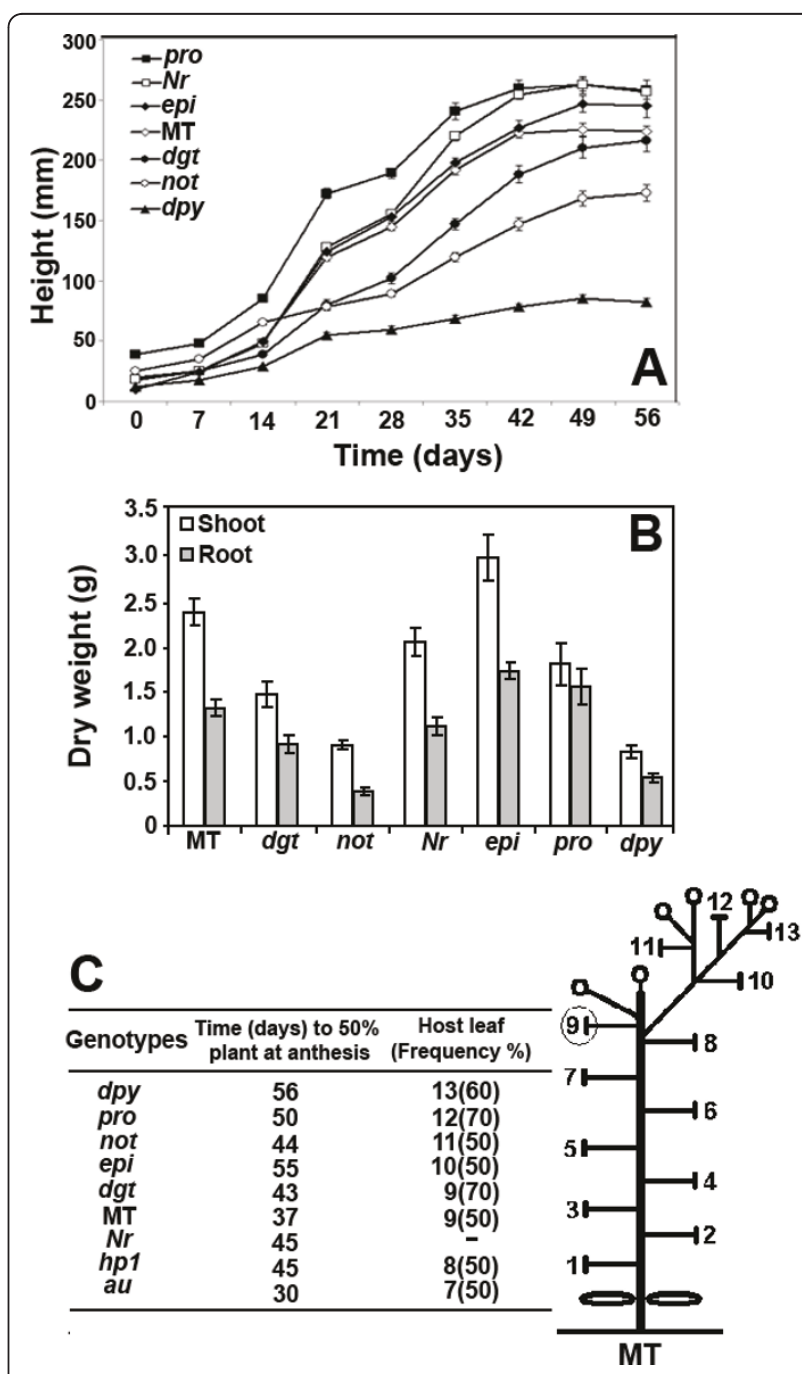

Figure 4 Growth of hormone mutants in the MT background under greenhouse conditions. (A) Growth curves of hormone mutants. (B) Dry weight of shoots (open bars) and roots (closed bars) in 60-day-old plants $(n=7)$. (C) Schematic representation of a 60-day-old MT plant growing in a 100-mL pot. T-shaped bars represent leaves with five leaflets (except for leaves 1 and 2, which usually have three leaflets) and small circles represent inflorescences with 5-8 flowers. Leaf 9 was highlighted for being the most frequent host of the first inflorescence in MT. This varies between mutants, the most frequent position is shown in the adjacent table with the frequency between brackets. This parameter, as well as time to anthesis in $50 \%$ of plants is indicative of developmental alterations that could increase or decrease vegetative development, in opposition to flowering. Note that MT has determinate growth (formation of two consecutive inflorescences) due to the presence of the self-pruning ( $s p$ ) mutation. None of the introgressed mutants altered this trait in the MT background. 
and expansion [57,58], GA-constitutive plants (pro) were considerably taller than the MT control (Figure 4A), whereas mutants with reduced sensitivity to auxin $(d g t)$ showed decreased dry weight in both shoots and roots (Figure 4B). Both stem height and dry mass were reduced in $\mathrm{ABA}$ and $\mathrm{BR}$ deficient plants (not and dpy, respectively). In $\mathrm{ABA}$-deficient mutants this effect can be accounted for by a generally reduced plant turgor, which leads to wilting (Figure 1O), whereas an increased endogenous ethylene level had also been proposed as the cause of the stunted growth in these mutants [59]. The observation that neither stem height nor dry mass was reduced in the ethylene overproducer mutant epi as in the ABA-deficient mutant (Figure 4B) suggests the existence of more components in the ABA-ethylene interaction. In agreement with that, while exogenous ABA application [59] or grafting an ABA-deficient mutant onto wild-type rootstock [60] normalized ethylene production in these mutants, their growth was still less than wild-type plants, suggesting that wild-type ABA levels are optimal for growth. The increased dry weight of epi also points to ethylene having a complex dual role, which can be either stimulating [61] or inhibiting [62] growth.

\section{Flowering and fruit production}

A series of parameters related to reproductive development were analyzed in the introgressed hormone and photomorphogenic mutants (Figure $4 \mathrm{C}$ and Table 3 ). Under our growth conditions, all mutants (except $a u$ ) showed delayed anthesis when compared to MT (Figure 4C). This effect could be due to slower or more extended vegetative growth, which is evidenced as an increased number of leaves (or nodes) before the production of the first inflorescence. With the exception of $d g t$ and $h p 1$, all mutants with a delayed anthesis had an extended vegetative phase, with 10 to 13 leaves at the time of flowering, versus nine for MT (Figure 4C). BR deficiency (dpy), GA constitutive action (pro), ABA deficiency (not), and ethylene excess (epi) all extended vegetative growth. These results suggest a role for these hormones in the transition between vegetative and reproductive growth in tomato. The phytochrome deficient mutant au reached anthesis one week before MT, with a consistently reduced number of leaves at the onset of flowering. This points to an important role of phytochrome in tomato flowering, even when this species is considered to have little response to photoperiod [63].

Various agronomically important responses were assessed on the mutants from anthesis to fruit ripening (Table 3). The most relevant observations are summarized here: i) increase and decrease in number of flowers per inflorescence in $a u$ and pro, respectively; ii) a tendency in most mutants to develop two locules per fruit instead of three as MT, as well as supernumerary locules in pro; iii) expressive decrease in seed number per fruit in not, epi and $d p y$; iv) seed weight increase in epi, pro, $h p 1$, and not and decrease in gib3, dgt and $a u$; v) increase of fruit weight in epi and $h p 1$ and decrease in all other mutants, except au (which showed no change); vi) decreased yield (total fruit weight per plant) in $d g t$, not and dpy; vii) decrease in ripening time in epi and $a u$; viii) increased total soluble solids (TSS) in most mutants, mainly in pro, and decreased values in epi and dpy.

In agronomic terms, the most significant result was the observation that parthenocarpic as well as normally pollinated fruit of pro mutant showed increased TSS (Table 3). The pro mutation also led to a reduction in fruit weight but not in yield, whereas the gain in TSS was in excess of $60 \%$. Wild species of the former Lycopersicon genus can produce as much as double the TSS as tomato. However, inheritance of this trait is polygenic and the highest increase gained with major genes derived from wild species reported so far has been $20 \%$ $[64,65]$.

\section{Discussion}

In this work we present a collection of tomato mutations introgressed into the MT cultivar. Various hormone and photomorphogenetic mutants were introduced into this single genetic background in a short period of time and within limited growth facilities. This is a less labor-intensive approach than induced mutagenesis, which would require considerable infrastructure to screen a large amount of plants. Further, for some loci, particularly those that are already knocked-out in the chosen model, the introgression of functional alleles may be the only way to restore the phenotypic variation (i.e. the gene effect) in order to study gene function [66]. As proof of concept, we quickly introgressed into MT the wild type alleles Dwarf (D - Figure 5A), Self-pruning (Sp - Figure 5B) and Uniform ripening ( $U$ - Figure $5 \mathrm{C}$ ). $\mathrm{MT}$ itself harbors nonfunctional alleles of all these genes, which are responsible for the small size ( $d$ and $s p$ ), plant determinate growth $(s p)$ and uniform fruit color $(u)$ of the cultivar [4,13]. Serrani et al. [9] recently used MT to assess crosstalk between GA and auxin in the formation of parthenocarpic fruits in tomato. The authors also used MT $D$ and MT $S p$ as controls to MT itself and showed that, although MT harbors mutated versions of both genes $(d$ and $s p)$, no difference was observed in the evaluated responses between MT, MT D and MT $S p$. Further, since tomato is often used in grafting experiments [60], the longer stem of MT $D$ line has an obvious advantage in the grafting procedure.

In the newly introgressed genotypes, the reduced size of MT proved to be additive to all the hallmark 
Table 3 Parameters analyzed in flowers and fruits of hormone and photomorphogenic mutants in cv. Micro-Tom

\begin{tabular}{|c|c|c|c|c|c|c|c|c|c|c|}
\hline & $\begin{array}{l}\text { Flowers per } \\
\text { inflorescence } \\
(n=10)\end{array}$ & $\begin{array}{l}\text { Locules per fruit } \\
\text { (frequency, } n=10 \text { ) }\end{array}$ & $\begin{array}{l}\text { Seeds per fruit } \\
\quad(n=10)\end{array}$ & $\begin{array}{l}\text { Seed weight } \\
(\mathrm{mg}, \mathrm{n}=10)\end{array}$ & $\begin{array}{l}\text { Fruit weight } \\
(\mathrm{g}, \mathrm{n}=10)\end{array}$ & $\begin{array}{l}\text { Total fruit weight per } \\
\text { plant }(g, n=15)\end{array}$ & $\begin{array}{l}\text { Time (days) to } \\
\text { fruit ripening since } \\
\text { anthesis }(n=15)\end{array}$ & $\begin{array}{c}\text { TSS1 } \\
(n=12)\end{array}$ & $\begin{array}{c}\text { TSS2 } \\
(n=12)\end{array}$ & $\begin{array}{c}\text { TSS3 } \\
(n=12)\end{array}$ \\
\hline MT & $7.2 \pm 0.6$ & $3(70 \%)$ & $41.3 \pm 5.5$ & $2.3 \pm 0.04$ & $5.1 \pm 0.3$ & $43.4 \pm 1.9$ & $53.4 \pm 1,3$ & $5.3 \pm 0.1$ & $5.1 \pm 0.0$ & $4.6 \pm 0.1$ \\
\hline$d g t$ & $8.5 \pm 0.9$ & $2(55 \%)$ & $36.5 \pm 4.6$ & $2.2 \pm 0.02^{L}$ & $3.4 \pm 0.3^{L}$ & $28.6 \pm 1.8^{L}$ & $57.2 \pm 1,4$ & $5.8 \pm 0.2^{\mathrm{H}}$ & $5.6 \pm 0.2^{\mathrm{H}}$ & - \\
\hline not & $7.1 \pm 0.5$ & $2(70 \%)$ & $20.4 \pm 2.0^{L}$ & $2.5 \pm 0.03^{H}$ & $3.7 \pm 0.2^{L}$ & $22.2 \pm 2.6^{\mathrm{L}}$ & $56 \pm 0,7$ & $6.0 \pm 0.1^{\mathrm{H}}$ & $6.0 \pm 0.1^{\mathrm{H}}$ & - \\
\hline epi & $7.2 \pm 0.9$ & $2(70 \%)$ & $26.3 \pm 3.9^{L}$ & $3.0 \pm 0.02^{\mathrm{H}}$ & $11.8 \pm 0.5^{\mathrm{H}}$ & $33.6 \pm 4.8$ & $42.1 \pm 1,0^{L}$ & - & $4.6 \pm 0.1^{L}$ & - \\
\hline pro $^{a}$ & $4.6 \pm 0.4^{\llcorner}$ & $4(85 \%)^{\mathrm{H}}$ & - & - & $3.4 \pm 0.2^{L}$ & $45.4 \pm 2.5$ & $54.8 \pm 2,3$ & $9.1 \pm 0.5^{\mathrm{H}}$ & $7.5 \pm 0.5^{\mathrm{H}}$ & - \\
\hline pro $^{b}$ & - & - & - & $2.7 \pm 0.03^{H}$ & - & - & - & $8.1 \pm 0.2^{\mathrm{H}}$ & - & - \\
\hline gib3 & - & - & - & $2.0 \pm 0.03^{L}$ & - & - & - & - & - & - \\
\hline$d p y$ & $6.1 \pm 0.2$ & $2(70 \%)$ & $22.4 \pm 3.8^{L}$ & $2.3 \pm 0.01$ & $4.0 \pm 0.4^{L}$ & $12.4 \pm 1.5^{L}$ & $58.7 \pm 2,6$ & $4.9 \pm 0.0^{L}$ & $4.8 \pm 0.1^{\llcorner}$ & - \\
\hline$a u$ & $10.8 \pm 0,5^{\mathrm{H}}$ & $2(70 \%)$ & $41 \pm 2.1$ & $2.2 \pm 0.01^{L}$ & $5.1 \pm 0.3$ & $40 \pm 0.8$ & $48.6 \pm 1.0^{L}$ & - & - & $5.0 \pm 0.1^{\mathrm{H}}$ \\
\hline hp1 & $8 \pm 0,6$ & $2(80 \%)$ & $31.1 \pm 1.8$ & $2.7 \pm 0.02^{\mathrm{H}}$ & $9.4 \pm 0.4^{\mathrm{H}}$ & $44.5 \pm 1.1$ & $58 \pm 2.0$ & - & & $5.4 \pm 0.1^{\mathrm{H}}$ \\
\hline
\end{tabular}

a Partenocarpic fruit, ${ }^{b}$ Fruit derived from artificial pollination, TSS1 $=$ Total Soluble Solids (Brix) measured in winter 2005, TSS2 = measured in summer 2006, TSS3 $=$ measured in autumn 2007. Mean values are followed by standard error (see Methods for experiment design). The letters $\mathrm{H}$ and $\mathrm{L}$ represent values statistically significantly higher or lower than $\mathrm{MT}$, respectively $(\mathrm{P}<0.05$, Student $t$-test). 


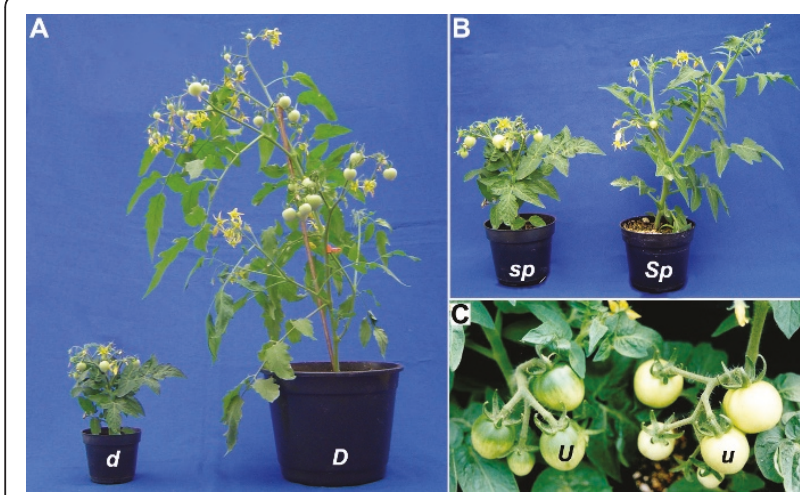

Figure 5 Lines near isogenic to MT harboring wild type alleles for DWARF (D), SELF-PRUNING (SP) and UNIFORM RIPENING (U) genes. (A) MT plant harboring the $D$ allele still shows a reduced size (as compared to common cultivars), but does not show rough leaves and is significantly bigger than MT harboring the $d$ allele. (B) The wild Sp allele in the MT background produces taller plants due to the extended growth of its vegetative apices, which denotes the indeterminate growth habit in opposition to the determinate one conferred by $s p$. The plants shown are of same age. Note the presence of leaves between inflorescences in Sp. (C) Plants harboring the $U$ allele develop fruits with a green shoulder. The pale bright color of MT fruits is probably a result not only of the $u$ mutation, but also uniform gray-green (ug).

phenotypes of either hormonal or photomorphogenetic mutations. Among them stand out the extreme dwarfism of GA-deficient ( $g i b 1, g i b 2$ and gib3) and BR insensitive/deficient mutants (cu3 and $d p y$ respectively) in the MT background. As already known, the dwarfism in MT is partially due to two recessive mutations, one of which is allelic to the aforementioned $d w \operatorname{wrf}[13,67]$, a gene in the BR biosynthesis pathway [68]. It follows from this that MT has reduced levels of BR, but without the dramatic effects evident in the extreme $d$ warf allele $d^{x}$ [68], which resembles cu3 and $d p y$ [23]. The additive phenotype of cu3 and dpy in MT suggests that the second mutation conferring dwarfism to MT is not related to BR. Thus, the presence of a second mutation affecting BR in MT would already result in a phenotype similar to $d p y$ and $c u 3$, as a consequence of the amplified effect of stacking mutant alleles of genes from the same pathway (see for instance Figure 2K). A further indication of this is the absence of rough leaves, a typical BRdeficiency phenotype, in MT plants lacking the $d$ allele but still harboring the second mutation conferring dwarfism (MT-D, Figure 5A). The reduction in size produced by GA-deficiency mutations in MT (Figure 1M), as well as the phenotype produced by the GA-constitutive mutation pro (Figure $1 \mathrm{~K}$ ) are in agreement with the previous suggestion that MT's dwarfism is not fully explained by GA effects either [13]. More conclusively, in contrast to every known GA-deficient mutant in tomato [22], MT shows a seed germination rate considered normal for a wild-type genotype (Figures 3A, 3B). Taken together, these results suggest that, in spite of being a mild BR mutant, MT and the collection itself are perfectly suitable tools for understanding plant hormone interactions. Moreover, if the event under study is influenced by $d w a r f$, or even any other mutation that MT already holds, the alternative of generating near isogenic lines (NILs) harboring the non-mutated allele as a control, such as MT $D$, MT $S p$ and MT $U$ presented here (Figure 5), fulfills the requirement of an appropriate control in the scientific method. Thus, all mutants obtained in MT by introgression (Table 1 and 2) or mutagenesis $[13,67]$ can be now easily combined with the $D, S \mathrm{p}$ and $U$ wild type alleles, as double mutants, when necessary.

Some of the alleles presented in the collection are not derived from other cultivars, but from related species within the Solanum section Lycopersicum. Ip and atv (Figure 2; Table 2) were introgressed from Solanum chmielewskii and S. cheesmaniae respectively, and cu3 from S. pimpinellifolium [24]. We have also previously described the introgression of $R g 1$ into MT [67], which increases in vitro regeneration capacity and was originally found in S. peruvianum [69]. The feasibility of comparative studies between alleles from related wild species in the MT background also makes the collection amenable for the study of natural genetic variation $[66,70]$. Combining natural genetic variation and other mutations in a single and more tractable genetic background will improve the capacity to observe novel phenotypes and gene interactions (epistasis). Most of the novel phenotypes reported here for previously-studied mutants is probably the consequence of such improvement in the capacity of observation, since they are very coherent with the function of the altered pathway. This seems to be the case of the presence of navel-like (and parthenocarpic) fruits, precocious germination and high brix in the GA-constitutive pro mutant; or the early flowering and fruit ripening of the phytochrome-mutant $a u$. However, we could not exclude the occurrence of some epistatic interactions with other mutations already present in the MT background, which may produce novel phenotypes such as the high dry weight of shoot and fruit observed in the ethylene overproducer epi as opposed to its original description [16].

Finally, various mutants from the collection presented here have already been used to investigate a wide range of topics in plant biology. Among them is the role of hormone classes in the light-induced anthocyanin accumulation in tomato hypocotyls [71], the multi-hormonal control of defense against herbivory in tomato [8], the role of plant hormones in the development of arbuscular mycorrhizae in tomato roots [72] and callus, shoot, and hairy-root formation in hormonal mutants [73]. Taken 
together, the present work is good evidence that the present collection of tomato mutants in a single genetic background is a suitable approach to conduct research in plant development.

\section{Methods}

\section{Breeding and cultivation}

Solanum lycopersicum L. cv. Micro-Tom (MT) plants were grown in a greenhouse with automatic irrigation (four times/day to field capacity), mean temperature of $28^{\circ} \mathrm{C}, 11.5 \mathrm{~h} / 13 \mathrm{~h}$ (winter/summer) photoperiod, and 250 to $350 \mu \mathrm{mol}$ photons $\mathrm{m}^{-2} \mathrm{sec}^{-1}$ PAR irradiance, attained by reduction of natural radiation with a reflecting mesh (Aluminet, Polysack Industrias Ltda, Leme, Brazil). Mutant seeds were germinated in trays containing a 1:1 mixture of commercial mix (Plantmax HT, Eucatex, Brazil) and expanded vermiculite, supplemented with $1 \mathrm{~g} \mathrm{~L}^{-1}$ 10:10:10 NPK and $4 \mathrm{~g} \mathrm{~L}^{-1}$ lime. Ten days after germination, plants were transferred to 150 $\mathrm{mL}$ (MT) or $10 \mathrm{~L}$ (other cultivars/species) pots containing soil mix. After crossing, mature fruits were harvested and the pulp removed from the seed by inoculation and overnight fermentation with Saccharomyces cerevisae (Fermix, Brazil). Seeds were further washed and airdried in preparation for germination.

The mutations of interest were introgressed into the MT cultivar by a series of crosses and back-crosses (see Figure S1). Pollen was collected from parent plants and used to fertilize emasculated MT flowers (floral organs were ready for emasculation 35 days after sowing). The resulting $F_{1}$ hybrids were selfed to obtain recombinant $F_{2}$ populations, which were subsequently screened for compact size and the mutation of interest. The selected plants were backcrossed with MT up to the sixth generation $\left(\mathrm{BC}_{6}\right)$, selfing every second generation to screen for homozygous mutants. After $\mathrm{BC}_{6} \mathrm{~F}_{2}$ the resulting genotypes can be considered near-isogenic lines [74]. For dominant mutations (e.g., Never ripe: $\mathrm{Nr}$ ), selfing was skipped until the $\mathrm{BC}_{6}$ generation, when $\mathrm{BC}_{6} \mathrm{~F}_{2}$ homozygous plants were identified through observation of their derived seedlings $\left(\mathrm{BC}_{6} \mathrm{~F}_{3}\right)$. $\mathrm{Nr}$ fruit was harvested unripe (since the mutation impairs normal ripening) and the ABA-deficient mutants sitiens (sit), flacca (flc) and notabilis (not) were harvested prematurely in order to avoid seed germination during fermentation. GA-deficient mutants (gib1, 2 and 3) were screened by germinating seeds onto wet filter paper. GA-deficient mutants do not normally germinate without exogenous GA application. After one week, germinating seeds were discarded, and the remaining batch was transferred to boxes containing filter paper soaked with $100 \mu \mathrm{M} \mathrm{GA}$. The seeds that germinated after one week of GA treatment were transferred to the greenhouse where the mutant phenotype (Figure 1M) was confirmed. The GAdeficiency phenotype was only observable when residual exogenous GA effects were negligible, which normally occurred two weeks after transferring the seedlings to the greenhouse. After this screening, $100 \mu \mathrm{M} \mathrm{GA}_{3}$ was sprayed fortnightly to allow flowering and fruit set [22].

\section{Seed germination and seedling measurements}

Assays on germination time and hypocotyl and root length of dark-grown seedlings were performed by sowing seeds onto wet filter paper in black plastic boxes. Time to germination (seeds with visible radicle) was assessed daily over five days in three replicate experiments (150 seeds per treatment). Seeds were counted in a dark room under green light. Hypocotyl and root lengths were measured after 10 days in 20 seedlings per treatment. For light treatments, seed germination was assessed in growth cabinets (Marconi, Piracicaba, Brazil) in vitro under light in a growth chamber $\left(25^{\circ} \mathrm{C}, 16 \mathrm{~h}\right.$ photoperiod, $55 \mu \mathrm{mol}$ photons $\left.\mathrm{m}^{-2} \mathrm{sec}^{-1} \mathrm{PAR}\right)$. Seed batches had been harvested at the same time from plants grown under the same conditions.

\section{Evaluation of vegetative and reproductive traits}

Plant height was measured weekly over 56 days in 15 plants per treatment. Stems and roots of 60-day-old plants $(n=7)$ were oven-dried at $60^{\circ} \mathrm{C}$ and their dry mass determined. Number of flowers was recorded in 15 plants starting from the first complete inflorescence $(\mathrm{n}=15)$. Time from anthesis to ripe fruit was measured in 15 fruits attached to different mother plants. Seeds per fruit, fruit weight and locule number per fruit were determined on 10 fruits per treatment $(n=10)$. Seed weight was determined for 100 seeds in 10 replicates (n = 10). Total fruit weight per plant (yield) was measured in 15 plants per treatment $(n=15)$. Total soluble solids (TSS) were measured in the flesh of ripe fruit using a digital refractometer (Atago PR-101) on 12 fruits per treatment $(n=12)$ derived from 12 different plants.

\section{Additional material}

Additional file 1: Figure S1. Scheme of the backcross introgression process.

\footnotetext{
Acknowledgements

To Dr. A. Levy (Weizmann Institute of Science - Israel) and Dr. Roger Chetelat (Tomato Genetics Resource Center, Davis, USA) for the donation of parental tomato seed. We also gratefully acknowledge the detailed comments of the two anonymous reviewers and to Shaun J. Curtin for improvements with the English language. FAPESP (grant number 02/00329-8) and CNPq (grant number 475494/03-2) are acknowledged for financial support.

Limited quantities of seed of the near-isogenic mutant lines presented here are available to interested researchers upon request.
} 


\section{Author details}

'Laboratory of Hormonal Control of Plant Development, Department of Biological Sciences (LCB), Escola Superior de Agricultura "Luiz de Queiroz" (ESALQ), Universidade de São Paulo (USP) - Av. Pádua Dias, 11, CP 09, CEP 13418-900 Piracicaba - SP, Brazil. ${ }^{2}$ Center for Nuclear Energy in Agriculture (CENA), USP, Av. Centenário, 303, CEP 13400-970 Piracicaba, SP, Brazil. ${ }^{3}$ Genetics and Developmental Biology Program, Plant and Soil Sciences Division, West Virginia University, 2090 Agricultural Sciences Building, Morgantown, WV 26506, USA.

\section{Authors' contributions}

MLC, RFC, LEP, SLC, AZ, and JEL performed crosses and characterized specific mutants into MT background. VAB and MLC participated in discussions, on mutant characterization, and worked on manuscript preparation. LEPP conceived the project, designed the introgressions, performed some backcrosses and worked on manuscript preparation. All authors read and approved the final manuscript.

\section{Competing interests}

The authors declare that they have no competing interests.

Received: 4 May 2011 Accepted: 29 June 2011 Published: 29 June 2011

\section{References}

1. Sol Genomics Network. [http://solgenomics.net].

2. The C. M Rick Tomato Genetics Resource Center. [http://tgrc.ucdavis.edu].

3. Pino LE, Lombardi-Crestana S, Azevedo MS, Scotton DC, Borgo L, Quecini V, Figueira A, Peres LEP: The $R g 1$ allele as a valuable tool for genetic transformation of the tomato Micro-Tom model system. Plant Methods 2010, 6:23.

4. Campos ML, Carvalho RF, Benedito VA, Peres LEP: Small and remarkable: the Micro-Tom model system as a tool to discover novel hormonal functions and interactions. Plant Signal Behav 2010, 5:50-54.

5. Scott J, Harbaugh B: Micro-Tom: A miniature dwarf tomato. Florida Agric Exp Station Circular 1989, 370:1-6.

6. Meissner R, Jacobson Y, Melamed S, Levyatuv S, Shalev G, Ashri A, Elkind Y, Levy A: A new model system for tomato genetics. Plant J 1997, 12:1465-1472.

7. Wang H, Schauer N, Usadel B, Frasse P, Zouine M, Hernould M, Latche A, Pech JC, Fernie AR, Bouzayen M: Regulatory features underlying pollination-dependent and -independent tomato fruit set revealed by transcript and primary metabolite profiling. Plant Cell 2009, 21:1428-1452.

8. Campos ML, Almeida M, Rossi ML, Martinelli AP, Junior CGL, Figueira A, Rampelotti-Ferreira FT, Vendramim JD, Benedito VA, Peres LEP: Brassinosteroids interact negatively with jasmonates in the formation of anti-herbivory traits in tomato. J Exp Bot 2009, 60:4347-4361.

9. Serrani JC, Carrera E, Ruiz-Rivero O, Gallego-Giraldo L, Peres LEP, GarciaMartinez JL: Inhibition of auxin transport from the ovary or from the apical shoot induces parthenocarpic fruit-set in tomato mediated by gibberellins. Plant Physiol 2010, 153:851-862.

10. Emmanuel E, Levy AA: Tomato mutants as tools for functional genomics. Curr Opin Plant Biol 2002, 5:112-117.

11. Tonsor SJ, Alonso-Blanco C, Koornneef M: Gene function beyond the single trait: natural variation, gene effects, and evolutionary ecology in Arabidopsis thaliana. Plant Cell Environ 2005, 28:2-20.

12. Dowell RD, Ryan O, Jansen A, Cheung D, Agarwala S, Danford T, Bernstein DA, Rolfe A, Heisler LE, Chin B, Nislow C, Giaever G, Phillipis PC, Fink GR, Gifford DK, Boone C: Genotype to phenotype: a complex problem. Science 2010, 328:469.

13. Martí E, Gisbert C, Bishop GJ, Dixon MS, Garcia-Martinez JL: Genetic and physiological characterization of tomato cv. Micro-Tom. J Exp Bot 2006, 57:2037-2047.

14. Oh K, Ivanchenko MG, White TJ, Lomax TL: The diageotropica gene of tomato encodes a cyclophilin: a novel player in auxin signaling. Planta 2006, 224:133-144.

15. Scott IM: Effects of gibberellin on shoot development in the dgt mutant of tomato. Ann Bot 1988, 61:389-392.

16. Fujino DW, Burger DW, Yang SF, Bradford KJ: Characterization of an ethylene overproducing mutant of tomato (Lycopersicon esculentum Mill cultivar VFN8). Plant Physiol 1988, 88:774-779.
17. Wilkinson JQ, Lanahan MB, Yen HC, Giovannoni JJ, Klee HJ: An ethyleneinducible component of signal-transduction encoded by Never-ripe. Science 1995, 270:1807-1809.

18. Lanahan $\mathrm{MB}$, Yen $\mathrm{HC}$, Giovannoni JJ, Klee HJ: The Never ripe mutation blocks ethylene perception in tomato. Plant Cell 1994, 6:521-530.

19. Bassel GW, Mullen RT, Bewley JD: procera is a putative DELLA mutant in tomato (Solanum lycopersicum): effects on the seed and vegetative plant. J Exp Bot 2008, 59:585-593.

20. van Tuinen A, Peters AHLJ, Kendrick RE, Zeevaart JAD, Koornneef M: Characterisation of the procera mutant of tomato and the interaction of gibberellins with end-of-day far-red light treatments. Physiol Plant 1999, 106:121-128.

21. Bensen RJ, Zeevaart JAD: Comparison of ent-kaurene synthetase A-activity and B-activity in cell-free-extracts from young tomato fruits of wild-type and gib-1, gib-2, and gib-3 tomato plants. J Plant Growth Regul 1990, 9:237-242

22. Koornneef M, Bosma TDG, Hanhart CJ, Vanderveen JH, Zeevaart JAD: The isolation and characterization of gibberellin-deficient mutants in tomato. Theor Appl Genet 1990, 80:852-857.

23. Koka CV, Cerny RE, Gardner RG, Noguchi T, Fujioka S, Takatsuto S, Yoshida S, Clouse SD: A putative role for the tomato genes DUMPY and CURL-3 in brassinosteroid biosynthesis and response. Plant Physiol 2000, 122:85-98.

24. Montoya T, Nomura T, Farrar K, Kaneta T, Yokota T, Bishop GJ: Cloning the tomato cur/3 gene highlights the putative dual role of the leucine-rich repeat receptor kinase tBRI1/SR160 in plant steroid hormone and peptide hormone signaling. Plant Cell 2002, 14:3163-3176.

25. Zeevaart J: Abscisic acid metabolism and its regulation. In Biochemistry and Molecular Biology of Plant Hormones. Edited by: Hooykaas P, Hall M, Libbenga K. Amsterdam: Elsevier Science; 1999:189-207.

26. Taylor IB, Burbidge A, Thompson AJ: Control of abscisic acid synthesis. J Exp Bot 2000, 51:1563-1574.

27. Burbidge A, Grieve TM, Jackson A, Thompson A, McCarty DR, Taylor IB: Characterization of the ABA-deficient tomato mutant notabilis and its relationship with maize Vp14. Plant J 1999, 17:427-431.

28. Frey A, Audran C, Marin E, Sotta B, Marion-Poll A: Engineering seed dormancy by the modification of zeaxanthin epoxidase gene expression. Plant Molecular Biology 1999, 39:1267-1274.

29. Fankhauser C, Chory J: Light control of plant development. Annu Rev Cell Dev Biol 1997, 13:203-229.

30. Smith H: Phytochromes and light signal perception by plants - an emerging synthesis. Nature 2000, 407:585-591.

31. Muramoto T, Kami C, Kataoka H, Iwata N, Linley PJ, Mukougawa $\mathrm{K}$, Yokota A, Kohchi T: The tomato photomorphogenetic mutant, aurea, is deficient in phytochromobilin synthase for phytochrome chromophore biosynthesis. Plant Cell Physiol 2005, 46:661-665.

32. Davis SJ, Bhoo SH, Durski AM, Walker JM, Vierstra RD: The heme-oxygenase family required for phytochrome chromophore biosynthesis is necessary for proper photomorphogenesis in higher plants. Plant Physiol 2001, 126:656-669

33. Koornneef M, Cone JW, Dekens RG, O'Herne-Robers EG, Spruit CJP, Kendrick RE: Photomorphogenic responses of long hypocotyl mutants of tomato. J Plant Physiol 1985, 120:153-165.

34. van Tuinen AV, Hanhart CJ, Kerckhoffs LHJ, Nagatani A, Boylan MT, Quail PH, Kendrick RE, Koornneef M: Analysis of phytochrome-deficient yellow-green-2 and aurea mutants of tomato. Plant J 1996, 9:173-182.

35. Liu YS, Roof S, Ye ZB, Barry C, van Tuinen A, Vrebalov J, Bowler C, Giovannoni J: Manipulation of light signal transduction as a means of modifying fruit nutritional quality in tomato. Proc Natl Acad Sci USA 2004, 101:9897-9902.

36. Mustilli AC, Fenzi F, Ciliento R, Alfano F, Bowler C: Phenotype of the tomato high pigment-2 mutant is caused by a mutation in the tomato homolog of DEETIOLATED1. Plant Cell 1999, 11:145-157.

37. Mochizuki T, Kamimura S: Photoselective method for selection of $h p$ at the cotyledon stage. Tomato Genet Coop Rep 1985, 35:12-13.

38. Kendrick RE, Kerckhoffs LHJ, van Tuinen A, Koornneef M: Photomorphogenic mutants of tomato. Plant Cell Environ 1997, 20:746-751.

39. Rick CM, Reeves AF, Zobel RW: Inheritance and linkage relations of four new mutants. Tomato Genet Coop Rep 1968, 18:34-35.

40. Rick CM: High soluble-solids content in large-fruited tomato lines derived from a wild green-fruited species. Hilgardia 1974, 42:493-510. 
41. Kucera B, Cohn MA, Leubner-Metzger G: Plant hormone interactions during seed dormancy release and germination. Seed Sci Res 2005, 15:281-307.

42. Brady SM, McCourt P: Hormone cross-talk in seed dormancy. J Plant Growth Regul 2003, 22:25-31.

43. Siriwitayawan G, Geneve RL, Downie AB: Seed germination of ethylene perception mutants of tomato and Arabidopsis. Seed Sci Res 2003, 13:303-314.

44. Chiwocha SDS, Cutler AJ, Abrams SR, Ambrose SJ, Yang J, Ross ARS, Kermode AR: The etr1-2 mutation in Arabidopsis thaliana affects the abscisic acid, auxin, cytokinin and gibberellin metabolic pathways during maintenance of seed dormancy, moist-chilling and germination. Plant J 2005, 32:35-48.

45. Steber $C M$, McCourt P: A role for brassinosteroids in germination in Arabidopsis. Plant Physiol 2001, 125:763-769.

46. Georghiou K, Kendrick RE: The germination characteristics of phytochrome-deficient aurea mutant tomato seeds. Physiol Plant 1991, 82:127-133.

47. Kerckhoffs LHJ, Schreuder MEL, van Tuinen A, Koornneef M, Kendrick RE: Phytochrome control of anthocyanin biosynthesis in tomato seedlings: analysis using photomorphogenic mutants. Photochem Photobiol 1997, 65:374-381.

48. Alabadí D, Blázquez MA: Molecular interactions between light and hormone signaling to control plant growth. Plant Mol Biol 2009, 69:409-417.

49. Halliday KJ, Fankhauser C: Phytochrome-hormonal signalling networks. New Phytol 2003, 157:449-463.

50. Kim BC, Soh MS, Kang BJ, Furuya M, Nam HG: Two dominant photomorphogenic mutations of Arabidopsis thaliana identified as suppressor mutations of hy2. Plant J 1996, 9:441-456.

51. Kraepiel Y, Agnes C, Thiery L, Maldiney R, Miginiac E, Delarue M: The growth of tomato (Lycopersicon esculentum Mill.) hypocotyls in the light and in darkness differentially involves auxin. Plant Sci 2001, 161:1067-1074.

52. Collett CE, Harberd NP, Leyser O: Hormonal interactions in the control of Arabidopsis hypocotyl elongation. Plant Physiol 2000, 124:553-561.

53. Barry CS, Fox EA, Yen HC, Lee S, Ying TJ, Grierson D, Giovannoni JJ: Analysis of the ethylene response in the epinastic mutant of tomato. Plant Physiol 2001, 127:58-66.

54. Li JM, Chory J: A putative leucine-rich repeat receptor kinase involved in brassinosteroid signal transduction. Cell 1997, 90:929-938.

55. Peres LEP, Zsögön A, Kerbauy GB: Abscisic acid and auxin accumulation in Catasetum fimbriatum roots growing in vitro with high sucrose and mannitol content. Biol Plantarum 2009, 53:560-564.

56. Drozdova IS, Bondar W, Bukhov NG, Kotov AA, Kotova LM, Maevskaya SN Mokronosov AT: Effects of light spectral quality on morphogenesis and source-sink relations in radish plants. Russ J Plant Physiol 2001, 48:415-420.

57. Jones AM, Im KH, Savka MA, Wu MJ, DeWitt NG, Shillito R, Binns AN: Auxindependent cell expansion mediated by overexpressed auxin-binding protein 1. Science 1998, 282:1114-1117.

58. Jones MG: Gibberellins and the procera mutant of tomato. Planta 1987 172:280-284

59. Sharp RE, LeNoble ME, Else MA, Thorne ET, Gherardi F: Endogenous ABA maintains shoot growth in tomato independently of effects on plant water balance: evidence for an interaction with ethylene. J Exp Bot 2000, 51:1575-1584

60. Dodd IC, Theobald JC, Richer SC, Davies WJ: Partial phenotypic reversion of ABA-deficient flacca tomato (Solanum lycopersicum) scions by a wild-type rootstock: normalizing shoot ethylene relations promotes leaf area but does not diminish whole plant transpiration rate. J Exp Bot 2009, 60:4029-4039.

61. Satler SO, Kende $\mathrm{H}$ : Ethylene and the growth of rice seedlings. Plant Physiol 1985, 79:194-198.

62. Abeles FB, Saltveit ME Jr: Ethylene in Plant Biology. 2 edition. San Diego: Academic Press; 1992.

63. Lifschitz E, Eviatar T, Rozman A, Goldshmidt A, Amsellem Z, Alvarez JP, Esched $Y$ : The tomato $F T$ ortholog triggers systemic signals that regulate growth and flowering and substitute for diverse environmental stimuli. Proc Natl Acad Sci USA 2006, 103:6398-6403.
64. Fridman E, Carrari F, Liu YS, Fernie AR, Zamir D: Zooming in on a quantitative trait for tomato yield using interspecific introgressions. Science 2004, 305:1786-1789.

65. Taylor IB: Biosystematics of the tomato. In The Tomato Crop: a scientific basis for improvement. Volume 1986. Edited by: Atherton JG, Rudich J. London: Chapman and Hall; 1-34.

66. Alonso-Blanco C, Koornneef M: Naturally occurring variation in Arabidopsis: an underexploited resource for plant genetics. Trends Plant Sci 2000, 5:22-29.

67. Lima JE, Carvalho RF, Neto AT, Figueira A, Peres LEP: Micro-MsK: a tomato genotype with miniature size, short life cycle, and improved in vitro shoot regeneration. Plant Sci 2004, 167:753-757

68. Bishop GJ, Nomura T, Yokota T, Harrison K, Noguchi T, Fujioka S, Takatsuto S, Jones JDG, Kamiya Y: The tomato DWARF enzyme catalyses C-6 oxidation in brassinosteroid biosynthesis. Proc Natl Acad Sci USA 1999, 96:1761-1766.

69. Koornneef M, Bade J, Hanhart C, Horsman K, Schel J, Soppe W, Verkerk R, Zabel P: Characterization and mapping of a gene controlling shoot regeneration in tomato. Plant $J$ 1993, 3:131-141.

70. Rick CM: Potential genetic resources in tomato species: clues from observations in native habitats. In Genes, Enzymes and Populations. Edited by: Hollaender A, Srb AM. New York: Plenum Press; 1973:255-269.

71. Carvalho RF, Quecini V, Peres LEP: Hormonal modulation of photomorphogenesis-controlled anthocyanin accumulation in tomato (Solanum lycopersicum L. cv. Micro-Tom) hypocotyls: physiological and genetic studies. Plant Sci 2010, 178:258-264

72. Zsögön A, Lambais MA, Benedito VA, Figueira AVO, Peres LEP: Reduced arbuscular mycorrhizal colonization in tomato ethylene mutants. Sci Agr 2008, 65:259-267.

73. Lima JE, Benedito VA, Figueira A, Peres LEP: Callus, shoot and hairy root formation in vitro is affected by the sensitivity to auxin and ethylene in tomato mutants. Plant Cell Rep 2009, 28:1169-1177.

74. Reid JB: Plant hormone mutants. J Plant Growth Reg 1993, 12:207-226.

doi:10.1186/1746-4811-7-18

Cite this article as: Carvalho et al.: Convergence of developmental mutants into a single tomato model system: 'Micro-Tom' as an effective toolkit for plant development research. Plant Methods 2011 7:18.

\section{Submit your next manuscript to BioMed Central and take full advantage of:}

- Convenient online submission

- Thorough peer review

- No space constraints or color figure charges

- Immediate publication on acceptance

- Inclusion in PubMed, CAS, Scopus and Google Scholar

- Research which is freely available for redistribution 